\title{
Analysis of the Natural Electric Field at Different Sea Depths
}

Peng Yu (D 15527176627@163.com )

Naval University of Engineering https://orcid.org/0000-0002-3934-9491

Jiawei Zhang

Navy uniersity of engineering

Jinfang Cheng

Navy university of engineering

Runxiang Jiang

Navy university of engineering

\section{Full paper}

Keywords: ocean, natural electric field, autonomous profiling drifter, South China sea Introduction

Posted Date: March 31st, 2020

DOl: https://doi.org/10.21203/rs.3.rs-19719/v1

License: (9) This work is licensed under a Creative Commons Attribution 4.0 International License. Read Full License

Version of Record: A version of this preprint was published at Journal of Instrumentation on January 12th, 2021. See the published version at https://doi.org/10.1088/1748-0221/16/01/P01006. 


\title{
Analysis of the Natural Electric Field at Different Sea Depths
}

\author{
Peng $\mathrm{YU}^{1 *}$, Jiawei ZHANG ${ }^{1}$ ， Jinfang CHENG $^{1}$, Runxiang JIANG ${ }^{2}$ \\ 1. College of Weaponry Engineering, Naval University of Engineering, Wuhan 430033 China; \\ 2. College of Electrical Engineering, Naval University of Engineering, Wuhan 430033 China.
}

\begin{abstract}
The natural electric field at the depth of $0 \sim 1500 \mathrm{~m}$ in high seas of South China Sea is obtained by using a new type of measuring device. The electric field data in the frequency range of $0.01 \sim 0.5 \mathrm{~Hz}$ and $0.5 \sim 30 \mathrm{~Hz}$ are analyzed respectively. The results show that the induced electric field generated by the surface wave (about $0.14 \mathrm{~Hz}$ in the experiment) is obvious at the depth of $50 \mathrm{~m}$ but can be ignored at the depth greater than $100 \mathrm{~m}$. When the depth increases from $50 \mathrm{~m}$ to $1500 \mathrm{~m}$, the peak value of the natural electric field gradually decreases. At the depth of $1000 \mathrm{~m}$, the peak value is $0.04 \sim 0.08 \mathrm{uV} / \mathrm{m}$ for electric field in $0.01 \sim 0.5 \mathrm{~Hz}$, and $0.07 \sim 0.1 \mathrm{uV} / \mathrm{m}$ for electric field in $0.5 \sim 30 \mathrm{~Hz}$. At last, the natural electric field in coastal waters near Sanya City where the water depth is $15 \mathrm{~m}$ is measured by means of a sinking device. The results show that, the peak value is about $2 \sim 4 \mathrm{uV} / \mathrm{m}$ for electric field in $0.01 \sim 0.5 \mathrm{~Hz}$ and $2 \mathrm{uV} / \mathrm{m}$ for electric field in $0.5 \sim 30 \mathrm{~Hz}$. By comparing the natural electric field between high seas and coastal waters, we find the latter has a larger peak value than the former at nearly the same water depth. In addition, line spectrum noise often occurs in coastal waters while little line spectrum noise in high seas when the water depth is more than $50 \mathrm{~m}$.
\end{abstract}

Key words: ocean; natural electric field; autonomous profiling drifter; South China sea

\section{Introduction}

The shaft-rate electric field originated from the rotation of ship's propeller has characteristics of low frequency (generally between $0.5 \sim 30 \mathrm{~Hz}$ ) and obvious line spectrum, which make it become an important source for ship detection and recognition (Young, 2012; Tatavarti, 2013; LI, 2015; Yu, 2019). In order to improve the detection and recognition ability of underwater targets based on the electric field characteristics, it is necessary to study the natural electric field in this frequency range.

Natural electric field has been studied since the last century, but it is mainly aimed at marine geophysics and oil-gas exploration. For example, Chave (1985) and Olsen (1997) studied the electric field generated by ocean tides, and the signal period is generally more than one day. Luther (1991) and Nilsson (2007) studied the electric field generated by the ocean current, and analyzed the current velocity and direction. Although the magnitude of electric field generated by the tide, internal wave and other similar phenomena is relatively large, the frequency is far lower than the ship's shaft-rate electric field. Eide (2007) considered that the induced electric field generated by ocean surface waves is mainly between $0.1 \sim 0.5 \mathrm{~Hz}$ based on the analysis of the previous work of others. This is a frequency range of interest when using electric field in underwater targets detection.

As for the marine electric field measuring device, bottom metering systems are usually used, such as Filloux (1973), Håland (2012), Flekkøy (2012) and Wang Meng (2017), all used a 3 -axis electric field sensor to measure the electric field signal on the seafloor. There are also very

*Corresponding author: Peng YU

E-mail Address: 15527176627@163.com 
few other measurement methods, such as Qualls (2015), who used an AUV equipped with the electric field sensor to measure the electric field near the hull.

It can be seen that most of the studies are based on the analysis of electric field data measured on the ocean floor or near the sea surface, but very few can obtain the electric field data of the entire ocean profile. In this paper, a new type of electric field measurement device based on the autonomous profiling drifter was used for the first time. The experiment was conducted in the high-seas area of South China Sea. The natural electric field in the depth range of $0 \sim 1500 \mathrm{~m}$ was measured by this device. Then we analyzed the time-domain and power spectral density (PSD) characteristics of the electric field in $0.01 \sim 0.5 \mathrm{~Hz}$ and $0.5 \sim 30 \mathrm{~Hz}$. To compare the difference of the electric field between the costal waters and high seas, we also measured the underwater electric field in coastal waters where the water depth is $15 \mathrm{~m}$ near Sanya, China. Note that, in this paper high seas refer to the sea area which is far from the mainland and has a water depth of several kilometers; while coastal waters refer to the area which is close to the mainland and has a water depth less than $60 \mathrm{~m}$.

The content of this paper is arranged as follows: in the second section, the basic structure of the electric field measuring device based on the autonomous profiling drifter is introduced, and the condition of sea trial in South China Sea is also introduced; in the third section, we analyze the electric field at different depths of high seas; in the fourth section, a bottom measuring device is used to record the electric field in coastal waters near Sanya City, then the natural electric field in coastal waters is compared with that of the high seas; in the fifth section, some conclusions are made based on the analysis above.

\section{Measurement technique and sea trail}

To measure the natural electric field at different depths, an electric field measuring device is used which combines the electric field measuring system with the autonomous profiling drifter, see in Fig.1. Note that UEP in Fig. 1 means underwater electric potential. The autonomous profiling drifter adjusts the buoyancy, making the measuring device move slowly or suspend at a set depth. And the UEP measuring unit is responsible for recording the electric field data at different depths. 


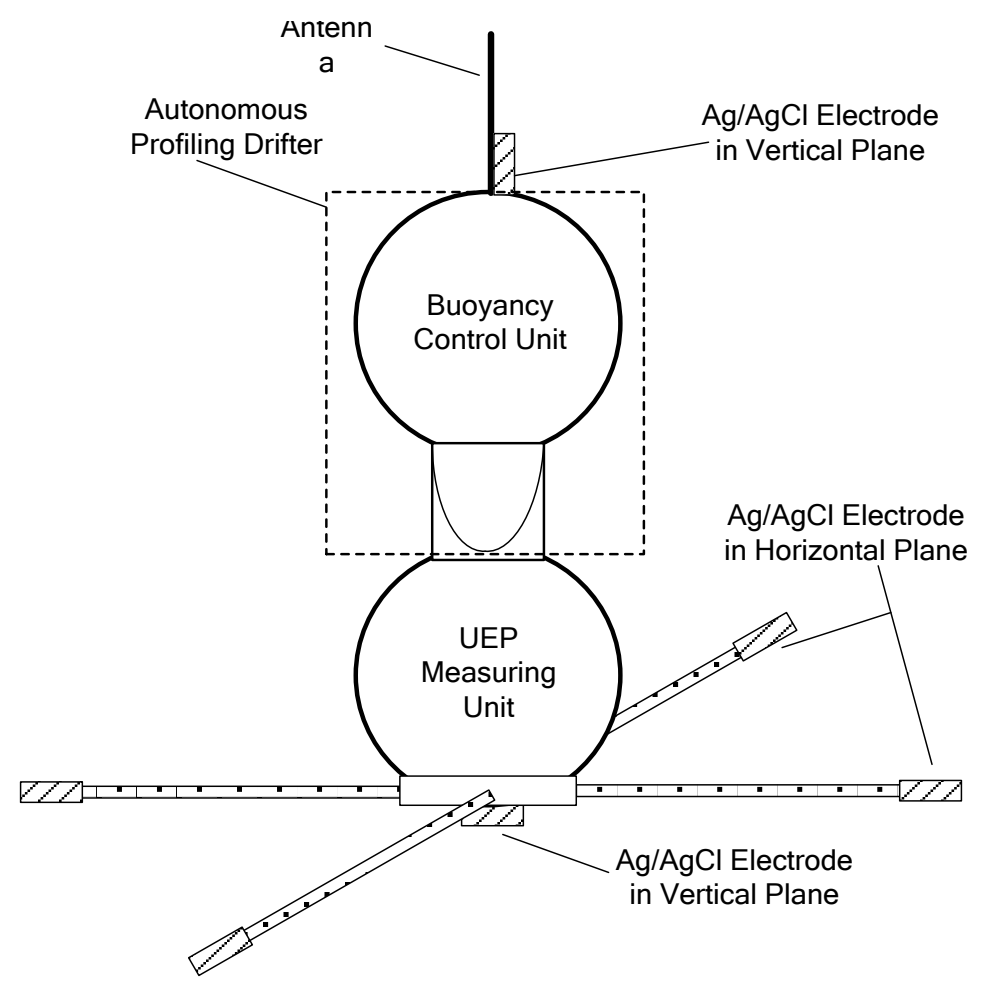

Fig.1 Sketch of the underwater electric field measuring device

We use three pairs of low-noise $\mathrm{Ag} / \mathrm{AgCl}$ electrodes and measure the $E_{x} 、 E_{y}$ and $E_{z}$

electric field components (note that $E_{z}$ represents the vertical component while $E_{x}, E_{y}$ are the horizontal components). The distance is $3 \mathrm{~m}$ between the horizontal electrodes and $1.6 \mathrm{~m}$ for the vertical electrodes. To avoid the electric field interference caused by the measuring device itself, carbon fiber electrode brackets are used. At the same time, the electronic instruments of the buoyancy adjusting unit and the electric field measuring unit are all placed in the pressure resistant glass ball. And water-tight cables are used for signal transmission.

The parameters of the electric field measuring unit are as follows: the noise of the $\mathrm{Ag} / \mathrm{AgCl}$ electrode is less than $1 \mathrm{nV} / \sqrt{\mathrm{Hz}} @ 1 \mathrm{~Hz}$, and the static potential difference of each pair of electrodes is less than $0.1 \mathrm{mV}$; the sampling rate of the measuring system is $100 \mathrm{~Hz}$, and the system noise is less than $4 \mathrm{nV} / \sqrt{\mathrm{Hz}} @ 1 \mathrm{~Hz}$.

The experiment was carried out in an area $300 \mathrm{~km}$ from the coast of southeastern Vietnam in South China Sea, in May 2019. The water depth of this area was about $3000 \mathrm{~m}$, and the sea wave height was about $1.0 \mathrm{~m}$. The sea trial is shown in Fig. 2. After the electric field measuring device (see in Fig.1(a)) was placed into the water, it automatically dived and suspended at a depth of 50 $\mathrm{m}$ for 1 hour, and then slowly dived to a depth of $2000 \mathrm{~m}$ at a speed lower than $0.06 \mathrm{~m} / \mathrm{s}$, and finally surfaced to transmit data. In the process of descent, the electric field data of different depths was recorded, and the attitude information was also recorded at the same time by an attitude sensor. 


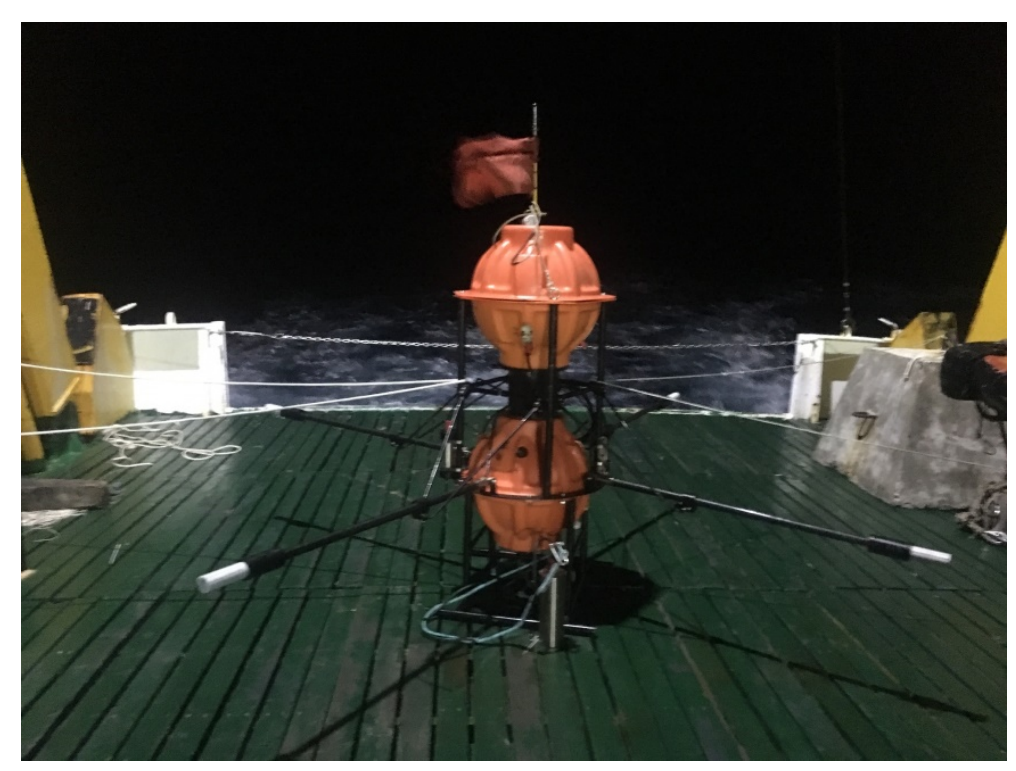

(a) Underwater electric field measuring device

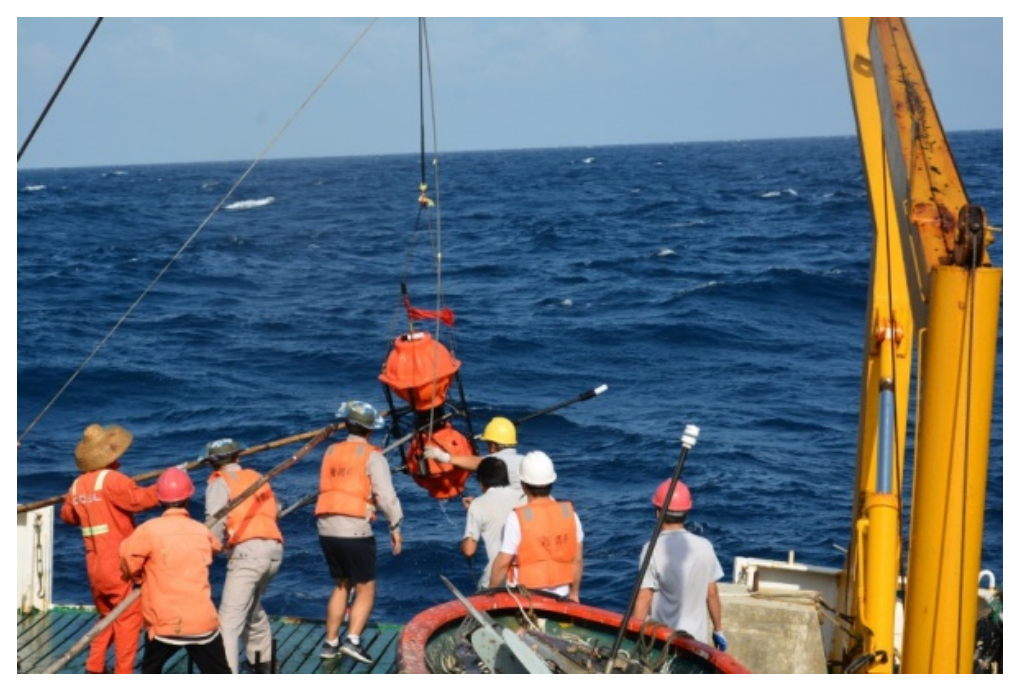

(b) Measuring device recovery

Fig.2 Sea trail of the electric field measuring device

\section{Natural electric field of high seas}

The time-domain and PSD characteristics of the natural electric field at different depths are analyzed. Depth range includes $20 \mathrm{~m}, 50 \mathrm{~m}, 100 \mathrm{~m}, 200 \mathrm{~m}, 500 \mathrm{~m}, 1000 \mathrm{~m}$ and $1500 \mathrm{~m}$ and the frequency range includes $0.01 \sim 0.5 \mathrm{~Hz}$ and $0.5 \sim 30 \mathrm{~Hz}$.

Firstly, the attitude of the measuring device is analyzed. The results show that at the depth less than $50 \mathrm{~m}$, the measuring device is in a low-frequency shaking state. The maximum pitch and roll angles both are about $7^{\circ}$, and the shaking frequency is close to the wave spectrum, about 0.14 $\mathrm{Hz}$; while the azimuth angle (rotating around the vertical direction) changes slowly, whose time period is more than 2 hours. When the measuring device starts to dive from $50 \mathrm{~m}$, the shaking amplitude starts to decrease rapidly. At the depth of $100 \mathrm{~m}$, the shaking amplitude both of the pitch angle and roll angles are less than $0.5^{\circ}$, while the azimuth angle changes more slowly than before. When the depth is more than $200 \mathrm{~m}$, the shaking amplitude of the measuring device is nearly 
unchanged although the depth continues to increase.

Based on the analysis of the underwater attitude of the measuring device, it can be seen that the measuring device is affected by the waves when the depth is less than $50 \mathrm{~m}$. When the depth is greater than $100 \mathrm{~m}$, it is nearly unaffected by the waves. Therefore, the electric field measured at a depth less than $50 \mathrm{~m}$ should have components of the induced electric field generated by the shaking of the measuring device itself. The analysis of the electric field at some depths is as follows.

(1) Depth at $50 \mathrm{~m}$

The time-domain and PSD characteristics of the natural electric field $(0.01 \sim 0.5 \mathrm{~Hz})$ are shown in Fig. 3 (a) and Fig. 3 (b), respectively. It can be seen from Fig. 3 (a) that the peak value of the electric field is in the level of $\mathrm{uV} / \mathrm{m}$. According to Fig. 3 (b), the PSD of $E_{x}, E_{y}$ and $E_{z}$ is basically the same level with each other and gradually decreases with the increase of frequency. At around $0.14 \mathrm{~Hz}$, the PSD of $E_{x} 、 E_{y}$ and $E_{z}$ increase significantly, and the PSD of $E_{z}$ is a little greater than that of the $E_{x}$ and $E_{y}$. And this phenomenon is more obvious when the depth is $20 \mathrm{~m}$, which is not shown because of limited space.

As we know, the $E_{z}$ component is more easily affected by the induced electric field generated by the wave motion cutting the north-south geomagnetic field (Yegorov, 2017; Szuts, 2012). As a result, the PSD in Fig. 3(b) clearly indicates that the electric field at this depth is affected by the surface wave.

At this depth, in addition to the induced electric field generated by the sea wave, the measurement platform is also in a low-frequency shaking state, so it will also generate an induced electric field of the corresponding frequency. As a result, the measured underwater electric field in the experiment will be slightly greater than the actual magnitude of the natural electric field.
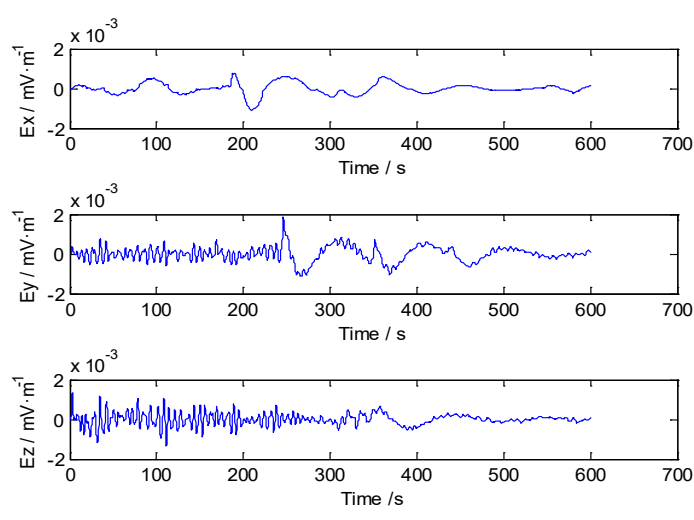

(a) Time-domain

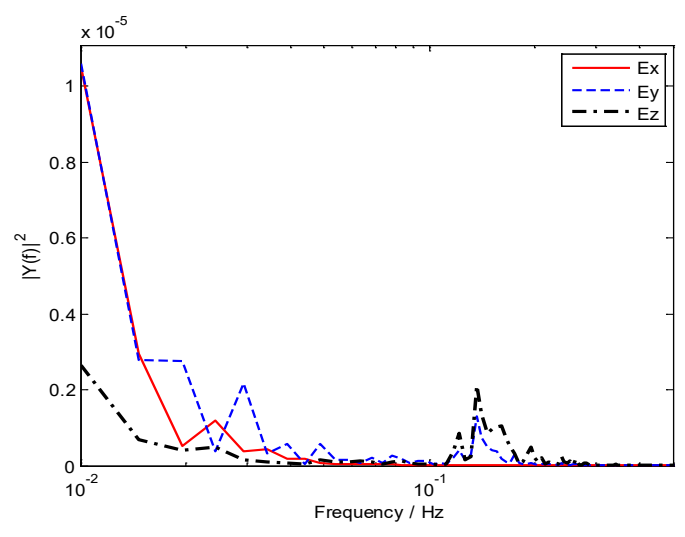

(b) PSD

Fig.3 Natural electric field $(0.01 \sim 0.5 \mathrm{~Hz})$

Fig. 4 shows the time-domain and PSD characteristics of electric field $(0.5 \sim 30 \mathrm{~Hz})$. From Fig. 4 (a), it can be seen that the peak values of both $E_{x}$ and $E_{y}$ are about $0.1 \mathrm{uV} / \mathrm{m}$, while $0.2 \mathrm{uV} / \mathrm{m}$ for $E_{z}$, which is higher than that of the horizontal components. It can also be seen from Fig. 4(b) 
that the PSD of $E_{z}$ is higher than that of the horizontal components. Note that the sharp pulses in Fig. 4 (a) and Fig. 4 (b) are generated by the interference of the buoyancy control unit.
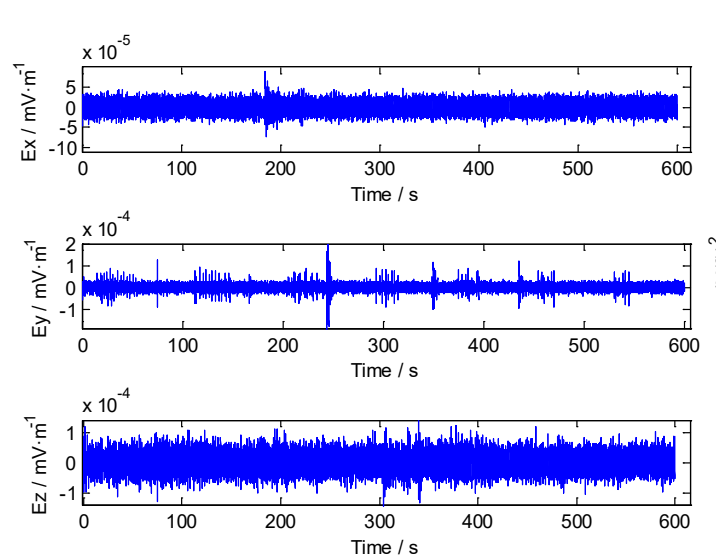

(a) Time-domain

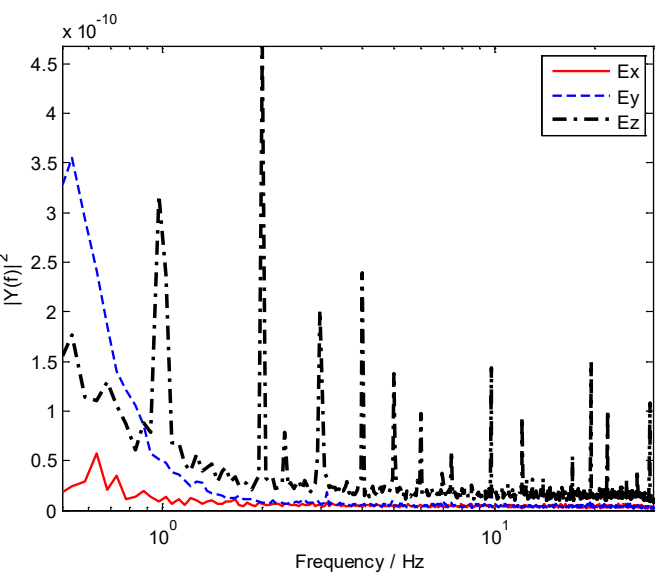

(b) PSD

Fig.4 Natural electric field $(0.5 \sim 30 \mathrm{~Hz})$

(2) Depth at $100 \mathrm{~m}$

Fig. 5 shows the time-domain and PSD characteristics of electric field $(0.01 \sim 0.5 \mathrm{~Hz})$ at depth of 100 m. Comparing Fig. 5 (a) with Fig. 3 (a), it can be seen that the peak value of the electric field at the depth of $100 \mathrm{~m}$ is significantly lower than that of the $50 \mathrm{~m}$. In addition, it can be seen from Fig. 5 (b) that the electric field energy is mainly concentrated in the frequency band below $0.02 \mathrm{~Hz}$. Comparing Fig. 5 (b) with Fig. 3 (b), we can see that the PSD at depth of $100 \mathrm{~m}$ does not increase at around $0.14 \mathrm{~Hz}$, indicating that the natural electric field at this depth is nearly not affected by the surface wave.
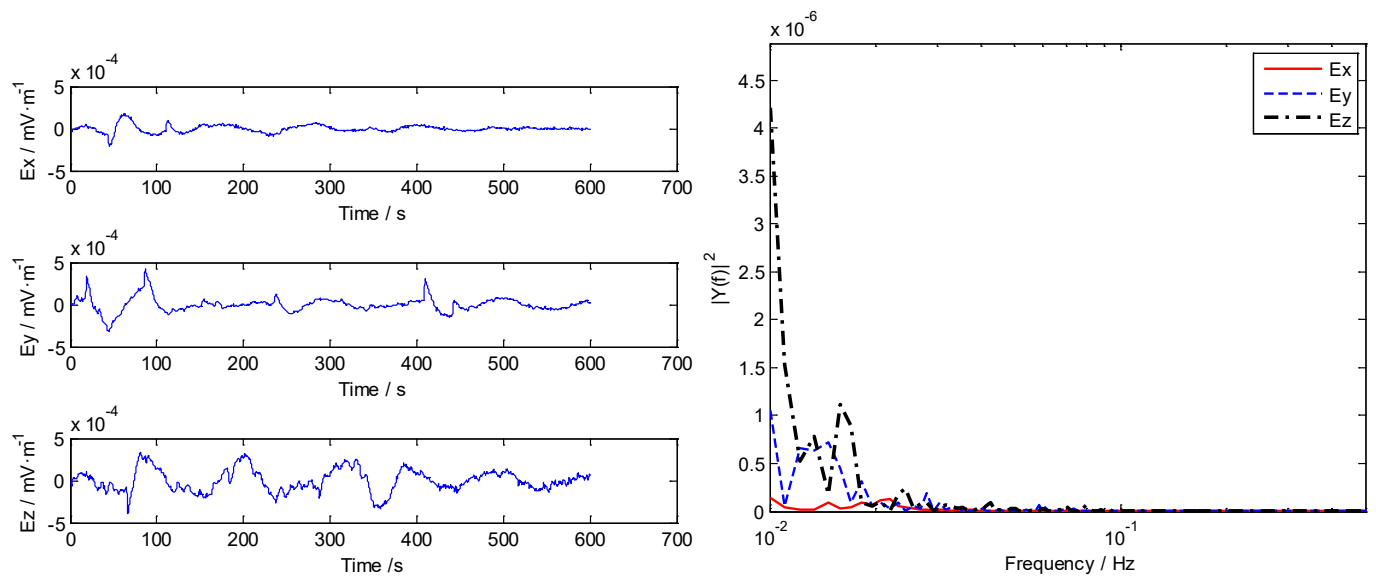

(a) Time-domain

(b) PSD

Fig.5 Natural electric field $(0.01 \sim 0.5 \mathrm{~Hz})$

(3) Depth at $200 \mathrm{~m}$

The time-domain and PSD characteristics of the electric field $(0.5 \sim 30 \mathrm{~Hz})$ are shown in Fig. 6. It can be seen that at the depth of $200 \mathrm{~m}$, the peak value of the electric field is further reduced compared with that of $100 \mathrm{~m}$. The PSD of $E_{z}$ is still larger than that of the horizontal components. It has been ruled out that this phenomenon is caused by the circuit board of the measuring device. It shows that the natural electric field of $0.5 \sim 30 \mathrm{~Hz}$ is not dominated by 
horizontal components in these depths.
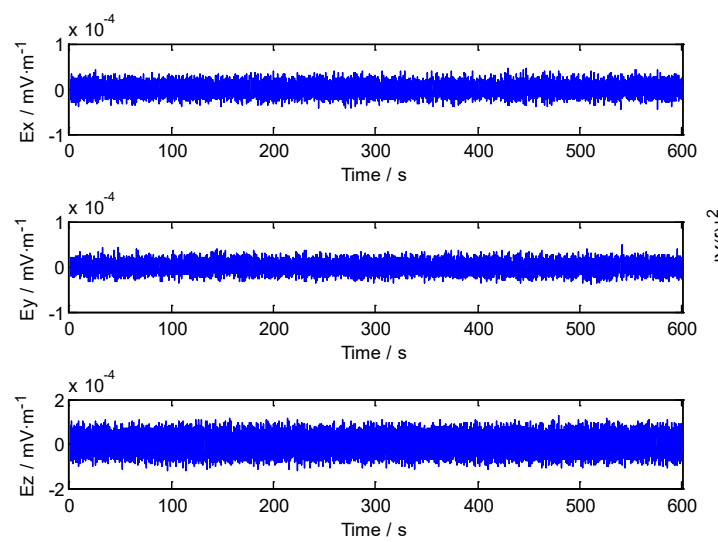

(a) Time-domain

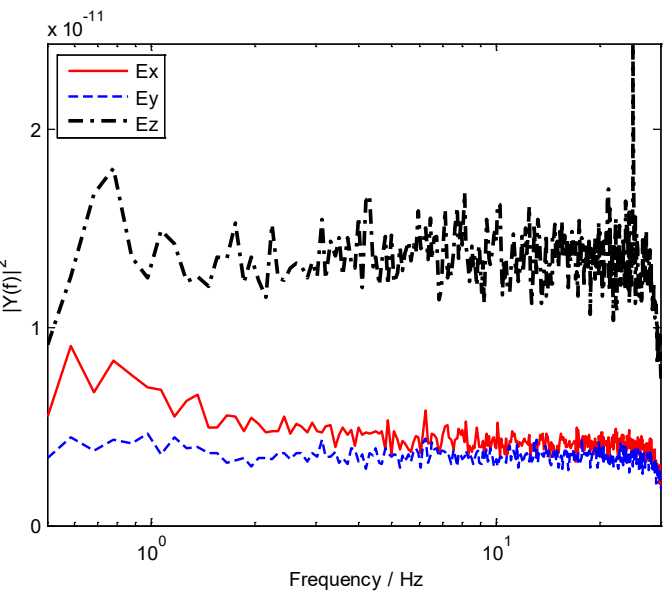

(b) PSD

Fig.6 Natural electric field $(0.5 \sim 30 \mathrm{~Hz})$

(4) Comparison of the electric field among different depths

To compare the natural electric field characteristics among different depths, the peak values of the electric field at different depths are summarized as shown in Table 1. We can get the following conclusions from Table 1 .

In the frequency of $0.01 \sim 0.5 \mathrm{~Hz}$ and $0.5 \sim 30 \mathrm{~Hz}$, the peak values of the $E_{x}$ and $E_{y}$

components are smaller than that of $E_{z}$. In other words, the noise of $E_{z}$ is higher than that of

$E_{x}$ and $E_{y}$. And this phenomenon is more obvious when the depth is less than $50 \mathrm{~m}$, while the difference gradually gets smaller in deeper depths.

Considering that the noise of the $E_{x}$ and $E_{y}$ is lower than that of $E_{z}$ component, and the horizontal component is dominant in the equivalent electric dipole of the underwater target, it is more suitable to use $E_{x}$ and $E_{y}$ components in underwater targets detection.

In the range of $0.01 \sim 0.5 \mathrm{~Hz}$, the peak value of the electric field decays faster at the depth of 50 500 m, but slower at the depth of 500 1500 m, which mainly due to the following reasons: a. The sea wave intensity decreases exponentially with the depth (the attenuation coefficient is $e^{2 \pi z / \lambda}$, where $z$ is the sea water depth and $\lambda$ is the wave wavelength). As a result, the wave strength decays faster at shallow depth, but tends to zero at deeper depths; $b$. The lower frequency electric field signal has a larger skin depth (Tyler 1998), for example, the skin depth of signals at $0.3 \mathrm{~Hz}$ is about $460 \mathrm{~m}$, so the attenuation trend is obvious within $500 \mathrm{~m}$ depth range; c. at $50 \mathrm{~m}$ depth, the measuring device is also in a low-frequency shaking state, resulting in a larger electric field strength than the actual, while at depths more than $100 \mathrm{~m}$, the measuring device's shaking is very wake, and the induced electric field generated by the measuring device itself can be ignored.

Similarly, for the electric field in $0.5 \sim 30 \mathrm{~Hz}$, the peak value decreases gradually when the depth increases from $50 \mathrm{~m}$ to $200 \mathrm{~m}$; while at a deeper depth more than $200 \mathrm{~m}$, the peak value is basically unchanged. Since this frequency range does not include the frequency of the surface 
wave motion, the attenuation trend of the electric field is mainly caused by the attenuation effect of the sea water, and the attenuation rate is also related to the skin depth of the signal.

Tab.1 Peak value of the natural electric field at different sea depths

\begin{tabular}{|c|c|c|c|c|}
\hline \multirow{2}{*}{$\begin{array}{c}\text { Depth } \\
\quad / \mathrm{m}\end{array}$} & \multicolumn{2}{|c|}{$0.01 \sim 0.5 \mathrm{~Hz} \quad / \mathrm{uV} \cdot \mathrm{m}^{-1}$} & \multicolumn{2}{|c|}{$0.5 \sim 30 \mathrm{~Hz} \quad / \mathrm{uV} \cdot \mathrm{m}^{-1}$} \\
\hline & Horizontal & Vertical & Horizontal & Vertical \\
\hline 20 & 4 & 4 & 0.8 & 1 \\
\hline 50 & 2 & 2 & 0.1 & 0.2 \\
\hline 100 & 0.2 & 0.8 & 0.08 & 0.15 \\
\hline 200 & 0.1 & 0.2 & 0.07 & 0.1 \\
\hline 500 & 0.06 & 0.08 & 0.08 & 0.1 \\
\hline 1000 & 0.04 & 0.08 & 0.07 & 0.1 \\
\hline 1500 & 0.05 & 0.08 & 0.08 & 0.1 \\
\hline
\end{tabular}

\section{Natural electric field of coastal waters}

In the section above, we measured the natural electric field at different depths, and its measurement area belongs to high seas where the water depth is thousands of meters. To compare it with coastal waters where the water depth is less than $60 \mathrm{~m}$, a long-term monitoring experiment was carried out in the shallow seas where the water depth was 15 m near Sanya City in September 2019.

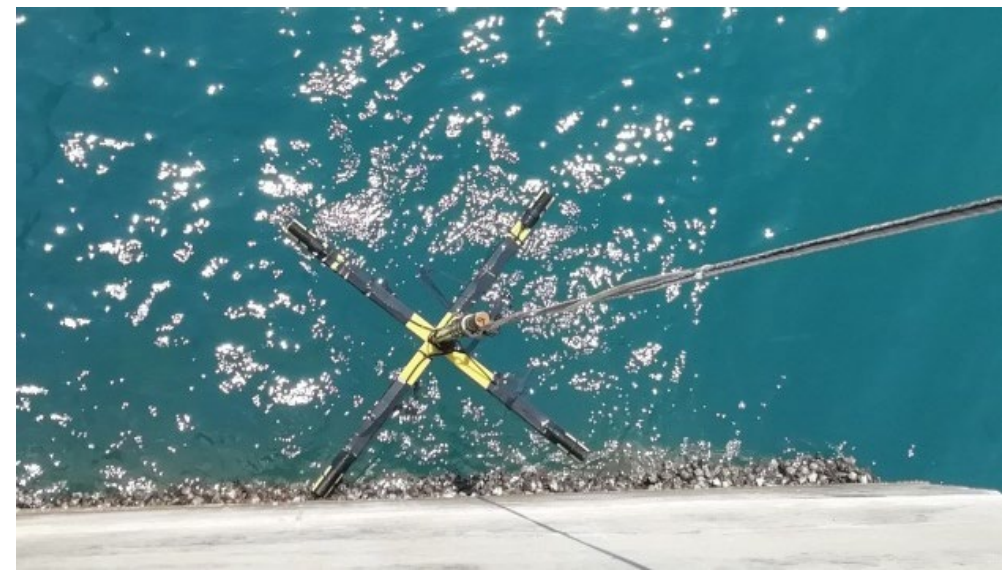

Fig.7 Underwater electric field measuring device at the sea bottom

To avoid the electric field interference caused by the measuring device itself, the measuring device was submerged at the sea bottom, and only non-metallic materials such as epoxy resins were used to fix the measuring electrodes $(\mathrm{Ag} / \mathrm{AgCl}$ electrodes $)$, and the signal was transmitted to the shore through the watertight cable for processing. The measuring platform did not shake with the sea water on the sea bottom, and the distance between each pair of $\mathrm{Ag} / \mathrm{AgCl}$ electrodes in three directions was $1 \mathrm{~m}$. The measuring device is shown in Fig. 7. The filter amplifier circuit is the same as the circuit used in Section 3, and the sampling rate is $200 \mathrm{~Hz}$.

Because we mainly study the signals in the frequency range of $0.01 \sim 0.5 \mathrm{~Hz}$ and $0.5 \sim 30 \mathrm{~Hz}$, the influence caused by tides is excluded. The analysis results show that the characteristics of natural electric field in $0.01 \sim 0.5 \mathrm{~Hz}$ change little within one day, but the electric field in $0.5 \sim 30$ $\mathrm{Hz}$ are often affected by artificial line spectrum signals. As a result, we choose the data in one time period near 10:00am to analyze where there are some line spectrum noise signals. In this period, the time-domain and PSD characteristics are shown in Fig. 8 and Fig. 9, respectively. 

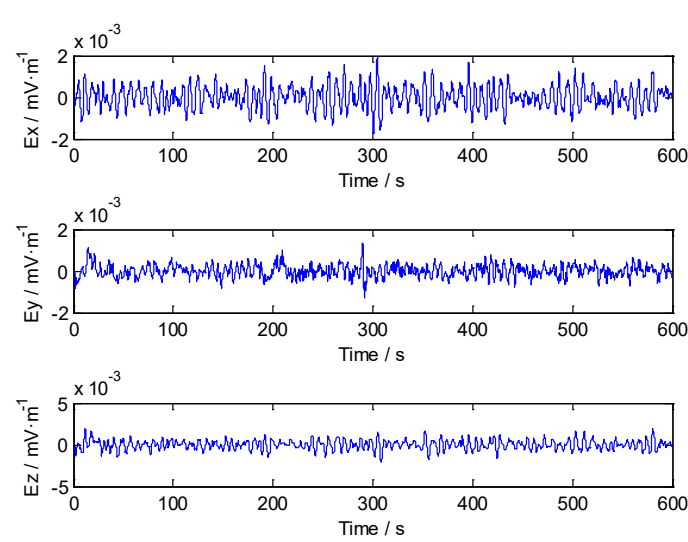

(a) Time-domain

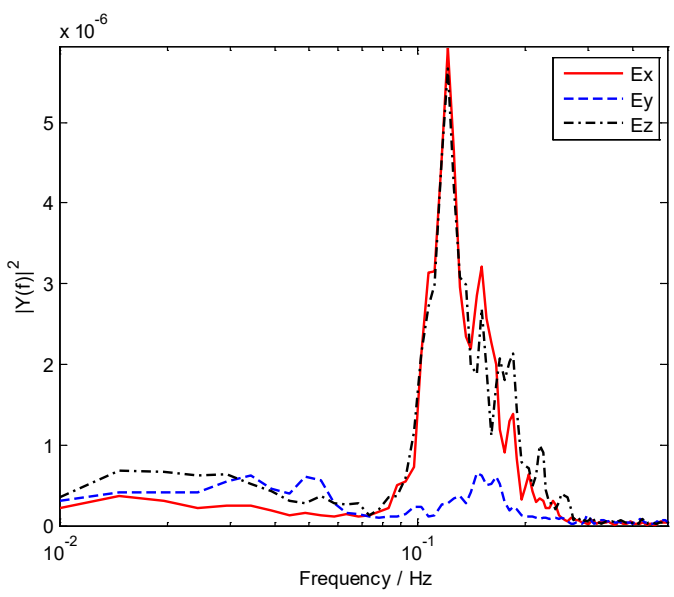

(b) PSD

Fig.8 Natural electric field $(0.01 \sim 0.5 \mathrm{~Hz})$
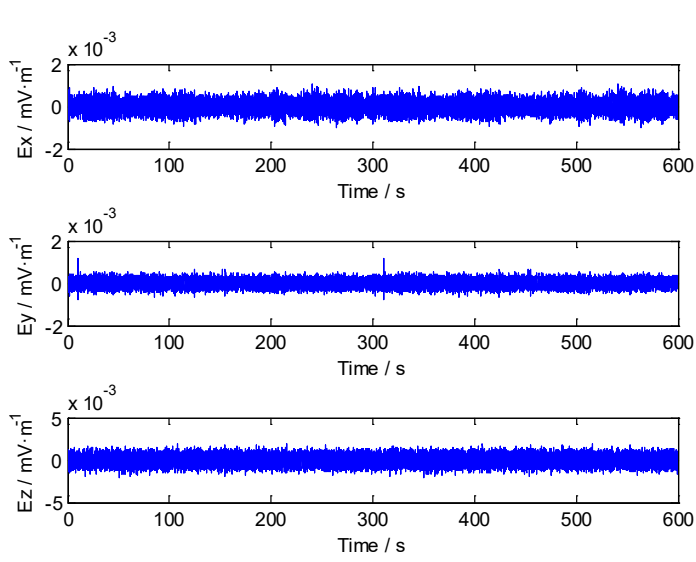

(a) Time-domain

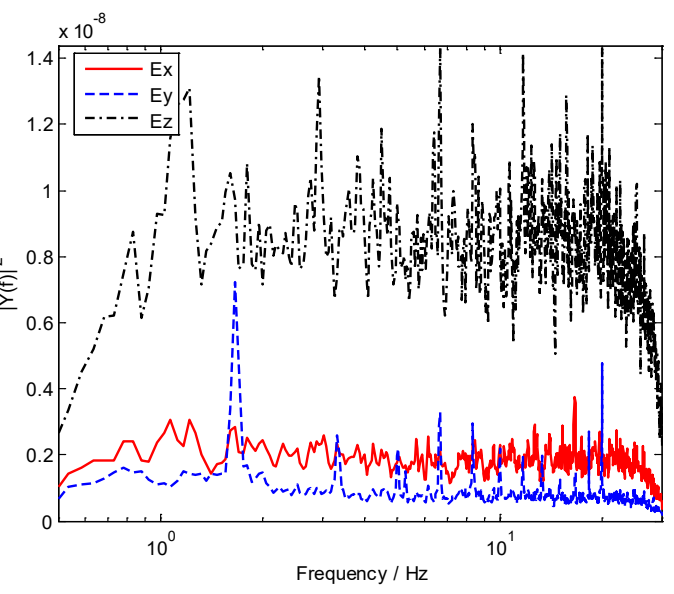

(b) PSD

Fig.9 Natural electric field $(0.5 \sim 30 \mathrm{~Hz})$

It can be seen from Fig. 8 that the peak value of the electric field in $0.01 \sim 0.5 \mathrm{~Hz}$ is about $2 \sim 4$ $\mathrm{uV} / \mathrm{m}$. At around $0.12 \mathrm{~Hz}$, the PSD of the three electric field components increase significantly, which is mainly caused by the induced electric field generated by the surface wave.

It can be seen from Fig. 9 that in the frequency range of $0.5 \sim 30 \mathrm{~Hz}$, the peak value of the electric field is about $2 \mathrm{uV} / \mathrm{m}$. The PSD of the vertical electric field component is greater than that of the horizontal components and this phenomenon is consistent with the results in section 3. Because the underwater electric field in coastal waters are more easily affected by human factors (Lin, 2007), some line spectrum signals within $0.5 \sim 30 \mathrm{~Hz}$ are found as shown in Fig. 9(b). And most of these line spectrum signals (the fundamental frequency is $1.6 \mathrm{~Hz}$ ) are generated by moving ships. In other times of the day, similar line spectrum signals also occur many times. While line spectrum signals are rarely found in high seas when the depth is more than $50 \mathrm{~m}$ in section 3 .

Comparing the electric field measured at the bottom of coastal waters with that measured at $20 \mathrm{~m}$ depth of high seas, we can find that they have the same level of peak values in $0.01 \sim 0.5 \mathrm{~Hz}$, but the peak value of the former is nearly 2 times larger than the latter in $0.5 \sim 30 \mathrm{~Hz}$. As the peak value of electric field in high seas will decrease gradually with deeper depth, making it far less than that of coastal waters. For example, at $100 \mathrm{~m}$ depth, the peak value of natural electric field $(0.5 \sim 30 \mathrm{~Hz})$ is only $5 \%$ of that measured in coastal waters. 


\section{Conclusions}

The natural electric field in the depth range of $0 \sim 1500 \mathrm{~m}$ in South China Sea is obtained by using an electric field measuring device based on the autonomous profiling drifter. The results show that the natural electric field (within $0.01 \sim 0.5 \mathrm{~Hz}$ ) is obviously affected by the surface waves at the depth less than $50 \mathrm{~m}$, but basically not affected by the surface waves at the depth more than $100 \mathrm{~m}$.

For the natural electric field within $0.5 \sim 30 \mathrm{~Hz}$, its peak value gradually decreases when the depth increases from $50 \mathrm{~m}$ to $200 \mathrm{~m}$. At the depth of $200 \mathrm{~m}$, the peak value of the natural electric field is about $0.1 \mathrm{uV} / \mathrm{m}$. But the peak value remains constant near a small value when the depth continues to go deeper.

At the end of the paper, we measured the natural electric field of coastal areas in Sanya City. By comparing the natural electric field between coastal waters and high seas, we find that the peak value of natural electric field (in $0.5 \sim 30 \mathrm{~Hz}$ ) in coastal waters is 2 times larger than that measured at $20 \mathrm{~m}$ depth of high seas, and nearly 20 times larger than that of deeper depths $(>100 \mathrm{~m})$ in high seas. In addition to that, line spectrum signals are rarely found in high seas when the water depth is more than $50 \mathrm{~m}$, while artificial line spectrum signals are often seen in one day of coastal waters. As a result, underwater targets detection in high seas will have a lower environmental noise than in coastal waters.

\section{Availability of data and materials}

The data used to support the findings of this study are available from the corresponding author upon request.

\section{Competing interests}

The author(s) declare no potential conflicts of interest with respect to the research, authorship, and/or publication of this article.

\section{Funding}

This work is funded by the research project "Deep Sea of Electromagnetic Detection System" (No.SQ2017WHZZB0202), initiated by Pilot National Laboratory for Marine Science and Technology in Qingdao, China.

\section{Authors' contributions}

Peng YU has performed all the analysis and drafted the work. Jiawei ZHANG, Jinfang CHENG and Runxiang JIANG gave overall guidance and helped in interpretations of the measured data. All authors read and approved the final manuscript.

\section{Acknowledgments}

We thank the Pilot National Laboratory for Marine Science and Technology in Qingdao for providing the opportunity to do many experiments in the open sea. We also appreciate the editors and reviewers for their guidance.

\section{References}

Chave A D and Filloux J H., 1985, Observation and interpretation of the seafloor vertical electric field in the eastern North Pacific: Geophysical Research Letters, 12(12), 793-796.

Eide, A. , 2007, Motion induced electromagnetic fields in the ocean: Exploratory data analysis and signal processing: Master's thesis, Universitetet i Tromsø.

Filloux, J. H., 1973, Techniques and instrumentation for study of natural electromagnetic induction at sea: Physics of the Earth and Planetary Interiors, 7(3), 323-338.

Flekkøy, E. G., Håland, E. and Måløy, K. J., 2012, Comparison of the low-frequency variations of 
the vertical and horizontal components of the electric background field at the sea bottom: Geophysics, 77(6), E391-E396.

Håland, E., Flekkøy, E. G. and Måløy, K. J., 2012, Vertical and horizontal components of the electric background field at the sea bottom: Geophysics, 77(1), E1-E8.

Tatavarti, R., Swain, S. K., Trinath, K., \& Arulmozhivarman, P. , 2013, Evolution of Non-Acoustic Detection Systems: Institute of Defence Scientists and Technologists Journal.

Luther, D. S., Filloux, J. H. and Chave, A. D., 1991, Low-frequency, motionally induced electromagnetic fields in the ocean: 2. Electric field and Eulerian current comparison: Journal of Geophysical Research: Oceans, 96(C7), 12797-12814.

LI Song, SHI Min, LUAN Jing-de, et al, 2015, The feature extraction and detection for shaft-rate electric field of a ship: Acta Armamentarii（in Chinese） 36(2), 220-224.

Lin Chunsheng, Gong Shenguang, 2007, Physical Field of Warships: Beijing Weapon Industry Press, China, 233-248.

Nilsson J A U, Sigray P and Tyler R H., 2007, Geoelectric monitoring of wind-driven barotropic transports in the Baltic Sea: Journal of Atmospheric and Oceanic Technology, 24(9), 1655-1664.

Olsen, N., 1997, Geomagnetic tides and related phenomena: In Tidal Phenomena Springer, Berlin, Heidelberg, 261-274.

Qualls, S. R., Osborn, J. M., Anderson, M. J., et a1, 2015, Underwater electric potential measurements using AUVs: In OCEANS 2015-MTS/IEEE Washington, 1-4.

Szuts, Z. B., 2012, Using motionally-induced electric signals to indirectly measure ocean velocity: Instrumental and theoretical developments: Progress in Oceanography, 96(1), 108-127.

Tyler, R. H., Sanford, T. B., and Unsworth, M. J.,1998, Propagation of electromagnetic fields in the coastal ocean with applications to underwater navigation and communication: Radio Science, 33(4), 967-987.

Wang M, Deng M, Wu Z L, et a1, 2017, New type deployed marine controlled source electromagnetic transmitter system and its experiment application: Chinese Journal of Geophysics, (in Chinese), 60(11): 4253-4261.

Yu, P., Cheng, J., and Zhang, J., 2019, Ship Target Tracking Using Underwater Electric Field: Progress In Electromagnetics Research, 86(1), 49-57.

Young, J. L., Sullivan, D. M., and Olsen, R. G., 2012, Investigation of ELF Signals Associated with Mine Warfare: A University of Idaho and Acoustic Research Detachment Collaboration, Phase Three: M. Sc. Thesis, Electrical and Computer Engineering University of Idaho, Moscow.

Yegorov, I. V., and Palshin, N. A., 2017, On the origin of background fluctuations in electric field measurements on the seafloor: Izvestiya, Physics of the Solid Earth, 53(3), 446-453. 
Figures

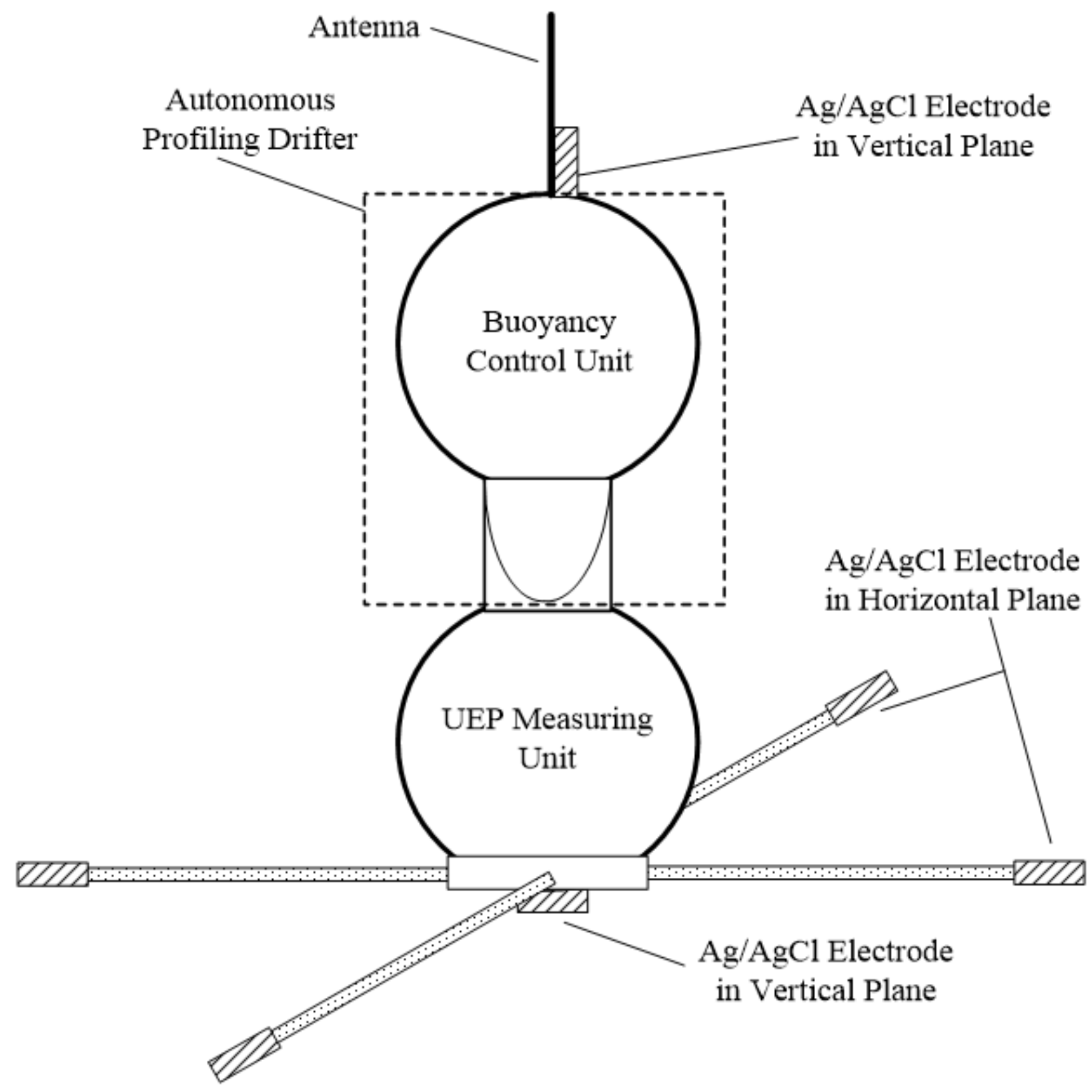

Figure 1

Sketch of the underwater electric field measuring device 


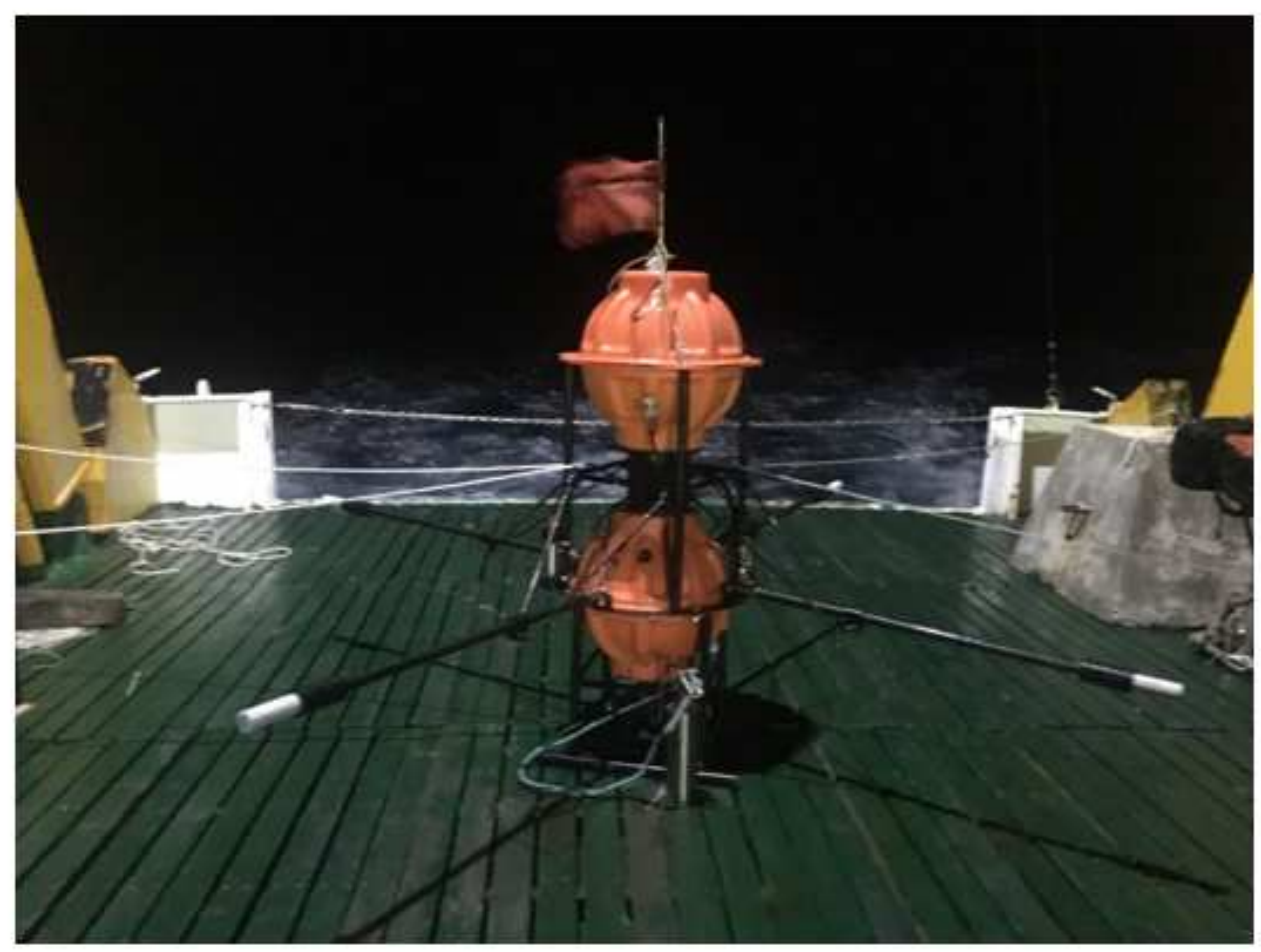

(a) Underwater electric field measuring device

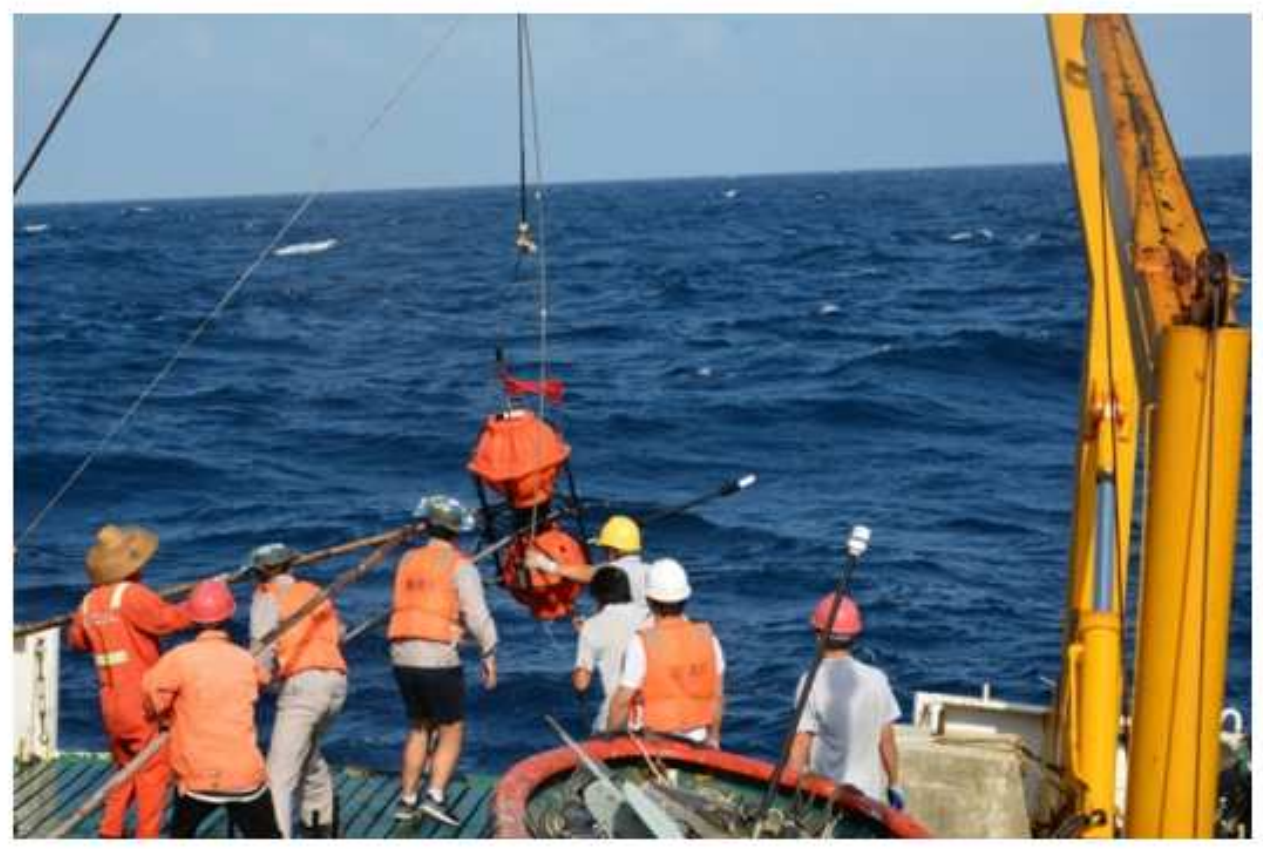

(b) Measuring device recovery

Figure 2

Sea trail of the electric field measuring device 

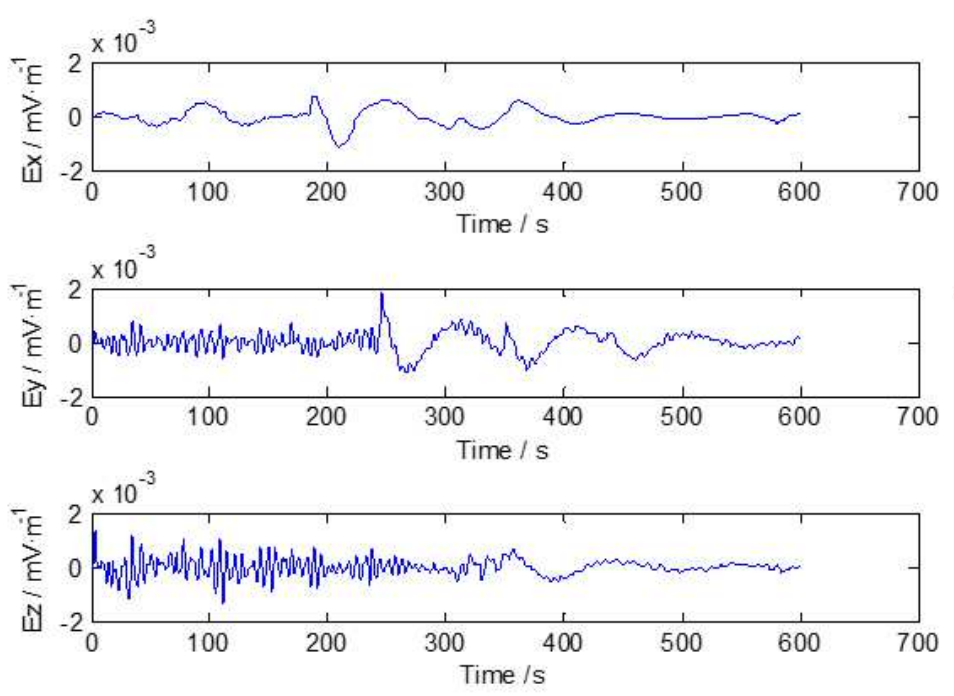

(a) Time-domain

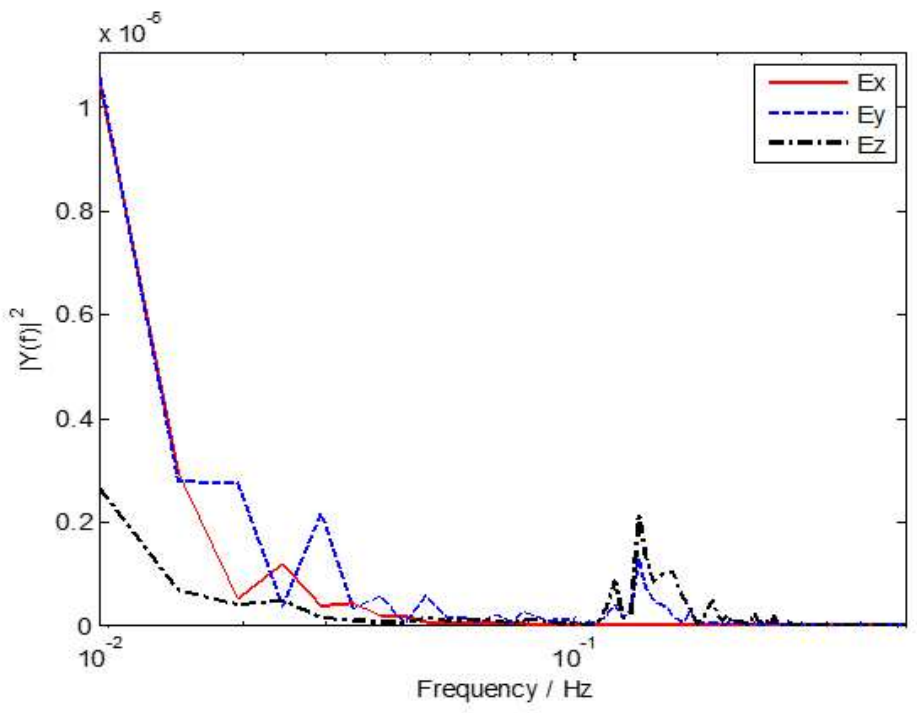

(b) PSD

\section{Figure 3}

Natural electric field $(0.01 \sim 0.5 \mathrm{~Hz})$
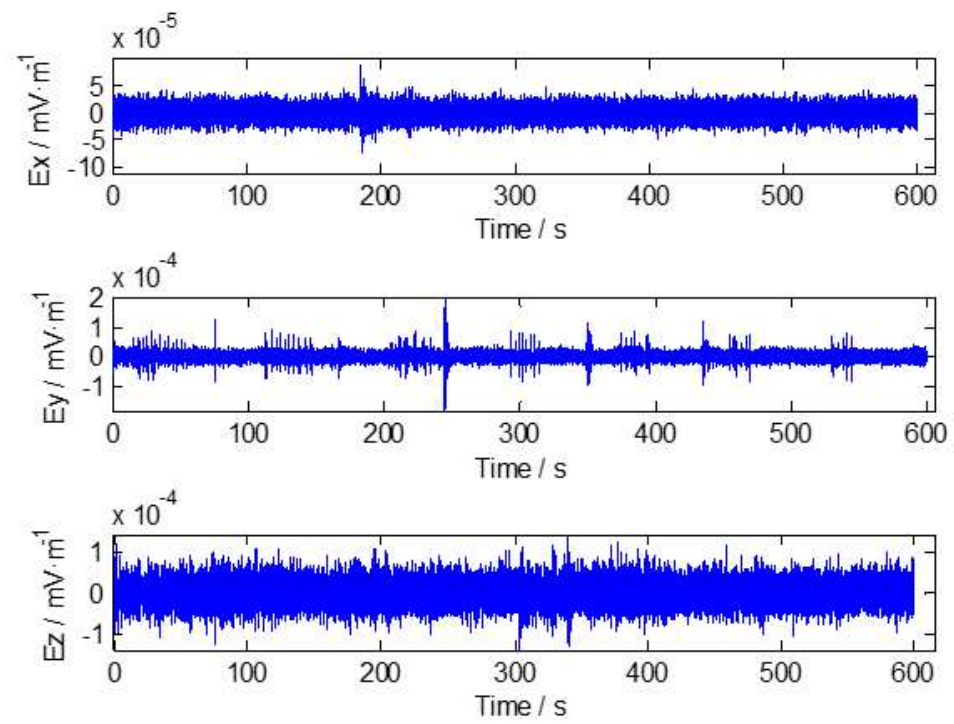

(a) Time-domain

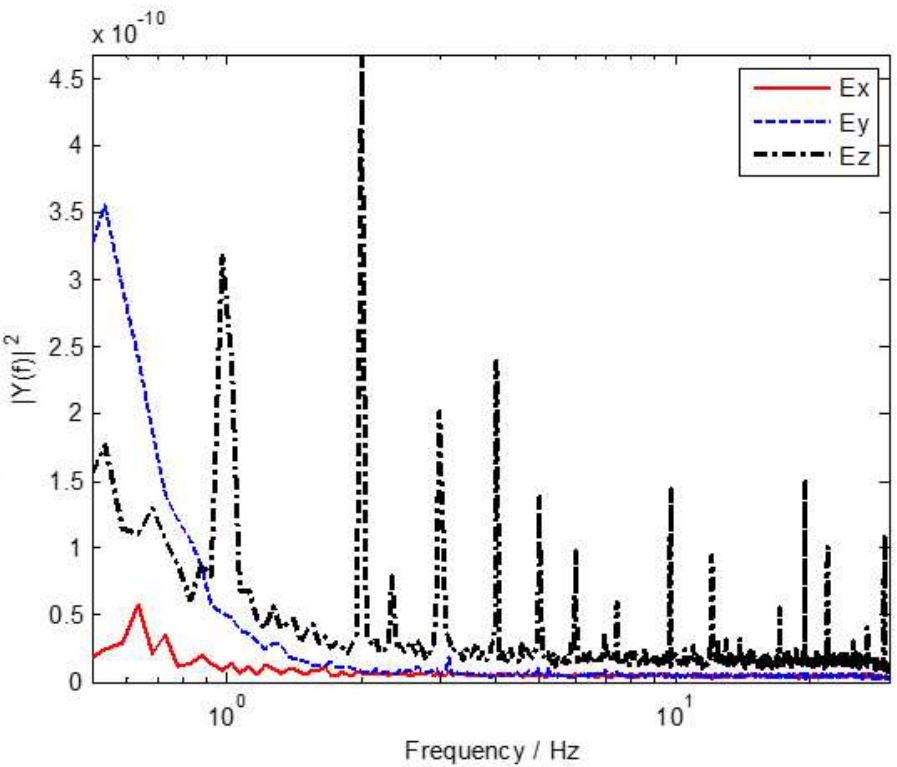

(b) PSD

Figure 4

Natural electric field $(0.5 \sim 30 \mathrm{~Hz})$ 

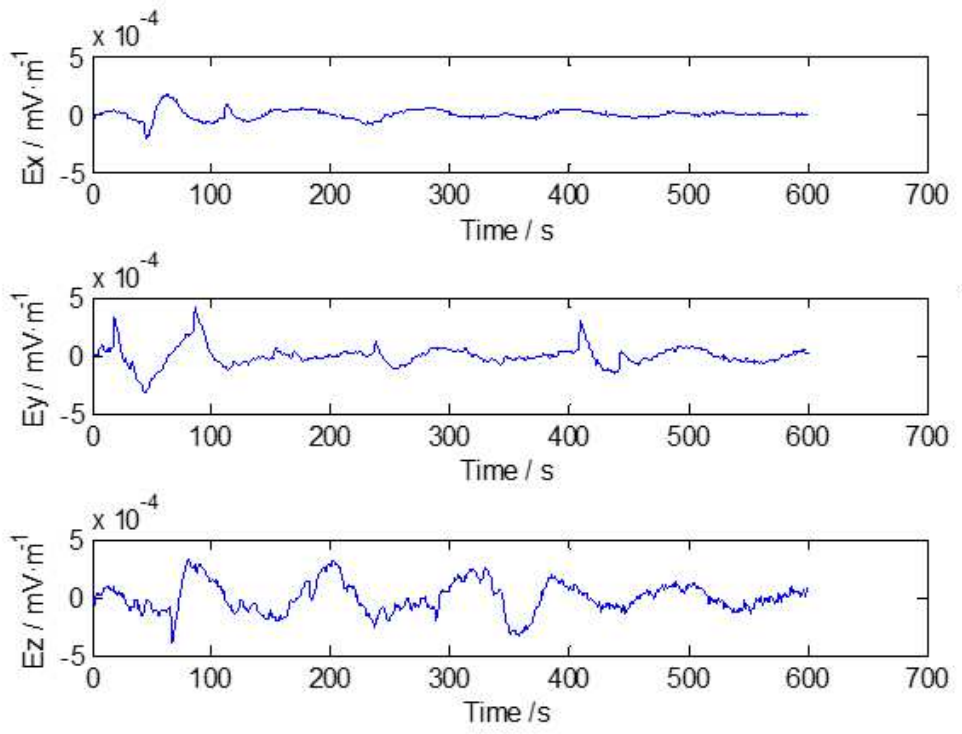

(a) Time-domain

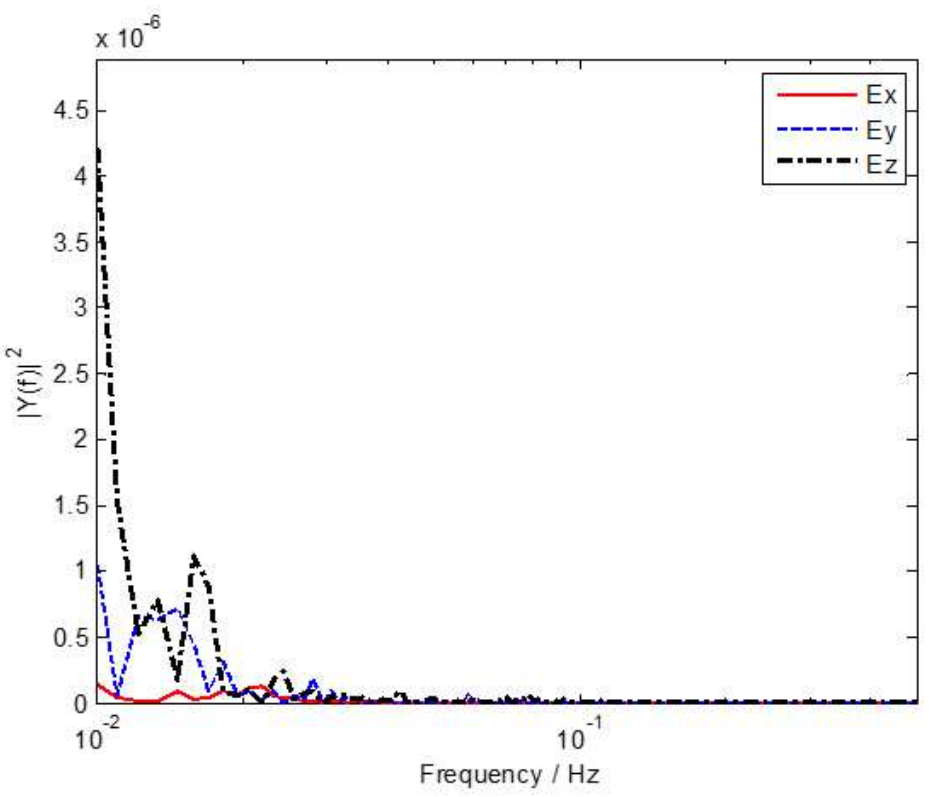

(b) PSD

\section{Figure 5}

Natural electric field $(0.01 \sim 0.5 \mathrm{~Hz})$
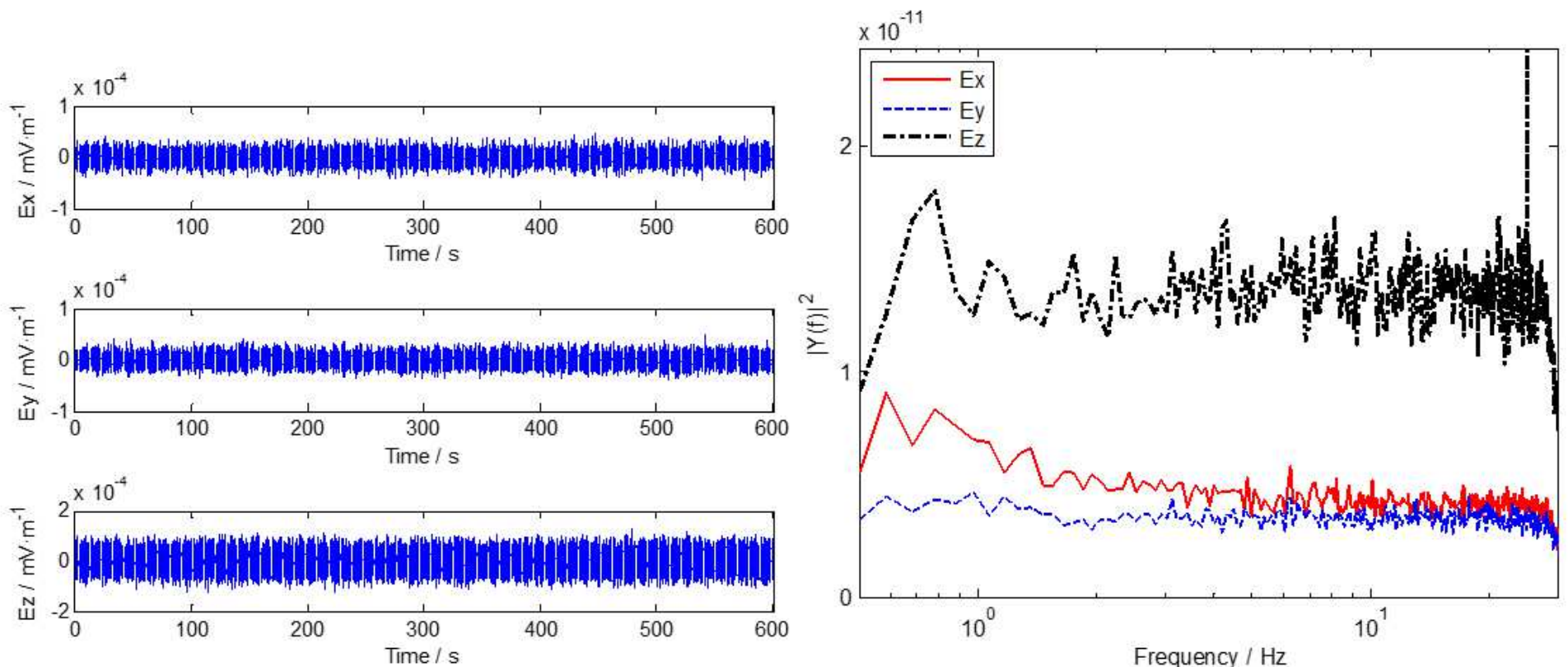

(a) Time-domain

(b) PSD

Figure 6

Natural electric field $(0.5 \sim 30 \mathrm{~Hz})$ 


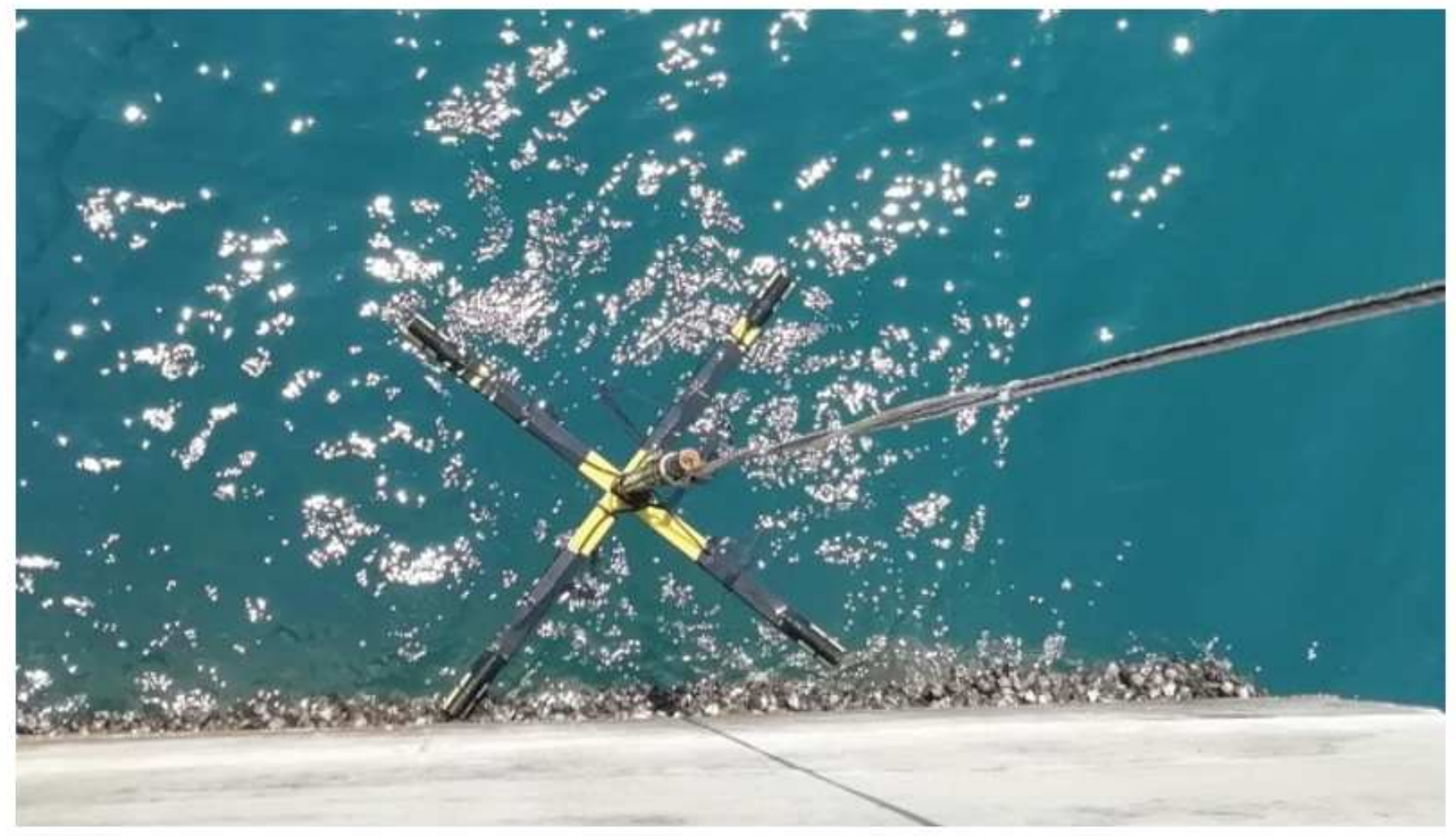

\section{Figure 7}

Underwater electric field measuring device at the sea bottom
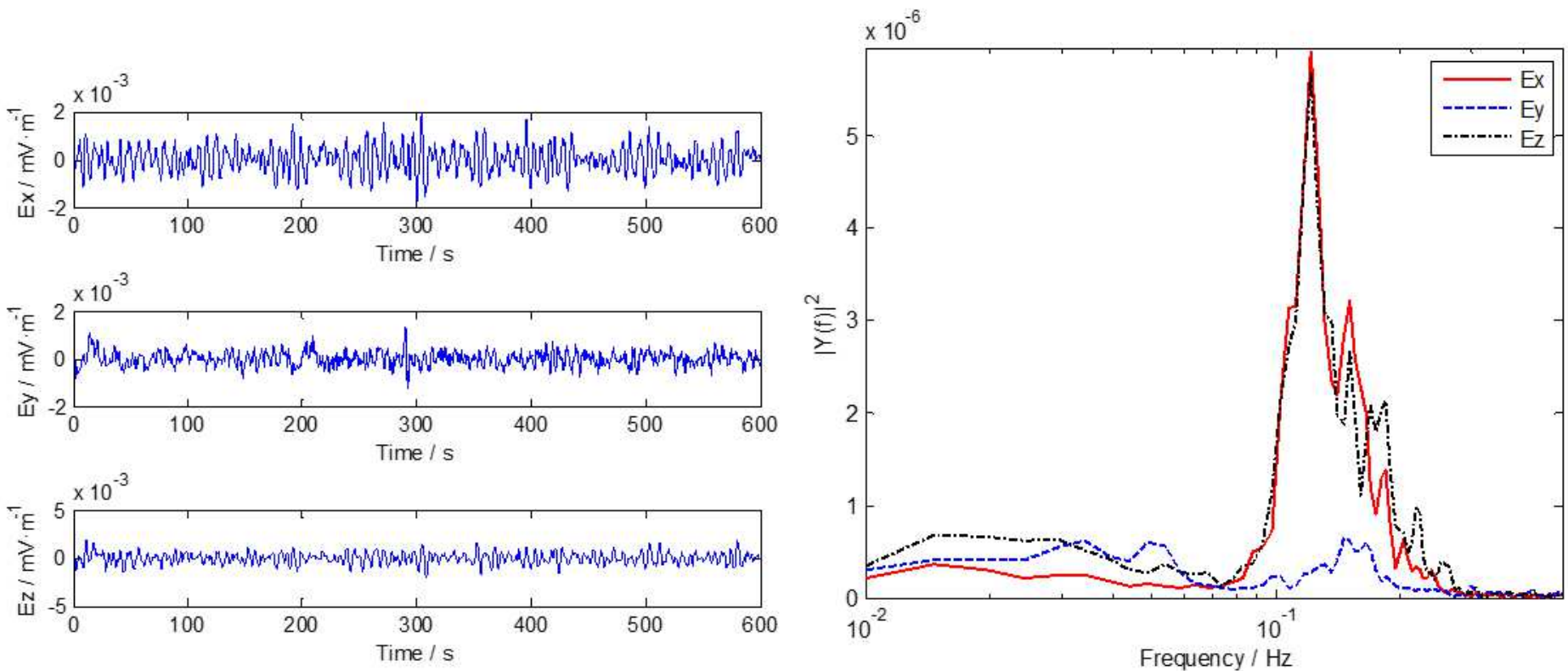

(a) Time-domain

(b) PSD

\section{Figure 8}

Natural electric field $(0.01 \sim 0.5 \mathrm{~Hz})$ 

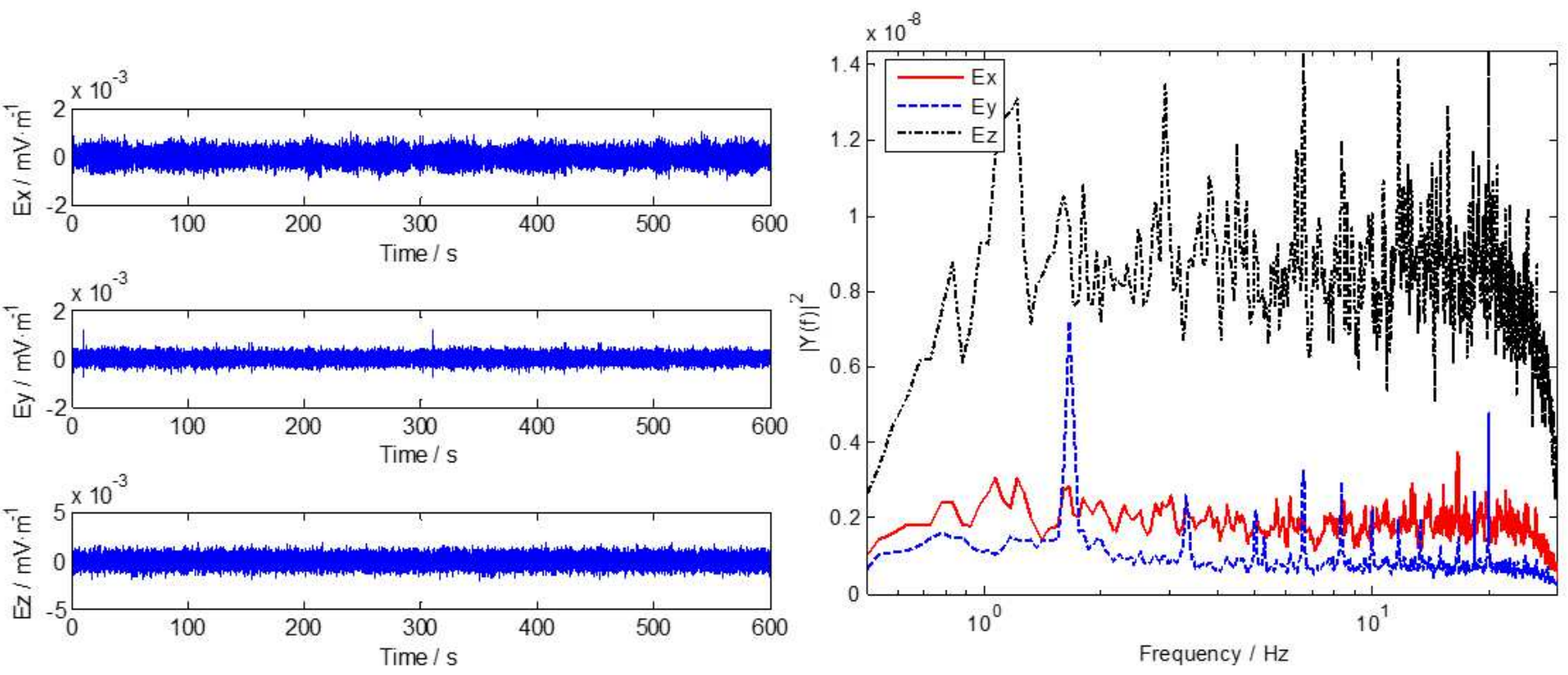

(a) Time-domain

(b) PSD

Figure 9

Natural electric field $(0.5 \sim 30 \mathrm{~Hz})$

\section{Supplementary Files}

This is a list of supplementary files associated with this preprint. Click to download.

- Graphic.docx 